\title{
Physicochemical and Thermal Characteristics of Pine Needle Biochar Briquetted Fuel using Soil, Lime and Cement as a Binder
}

\author{
Akanksha Kumain $^{1 *}$, T. K. Bhattacharya ${ }^{2}$ and Hemant Kumar Sharma ${ }^{2}$ \\ Department of Farm Machinery and Power Engineering College of Technology, GBPUA\&T, \\ Pantnagar, U.S. Nagar-263145, Uttarakhand, India \\ *Corresponding author
}

\section{A B S T R A C T}

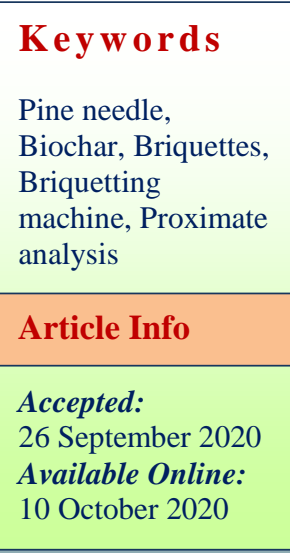

A large population of rural or hills of Uttarakhand is still facing the energy crisis in the household as well as for small and medium scale industries due to insufficient supply of fuel and electricity. The supply of coal and LPG is irregular for far-flung areas which make them bound to depend solely on wood for fuel. Therefore, a study was undertaken to evaluate the physical and thermal properties of pine needle biochar briquettes to check its feasibility as sustainable solid biofuel for the hills of Uttarakhand. Pine needle biomass was collected from the pine forest and converted into biochar. Further, biochar was mixed with three binders i.e. soil, cement and lime in different ratio on weight basis briquettes were formed using screw type briquetting machine. The physicochemical and thermal properties of briquettes were evaluated. The highest density of biochar briquettes was found to be $435.58 \mathrm{~kg} \mathrm{~m}^{-3}$ for ratio $\mathrm{B} 50: \mathrm{C} 50$ which comprise equal percentage $50 \%$ of biochar and cement as binder. The biochar binder ratio B50:L50 (biochar with lime) has the highest shattering resistance of $90.6 \%$. Pine needle biochar briquetting can be a solution by providing alternative household solid fuel replacing wood and coal which will help to save the environment by reducing the deforestation and fire hazard.

\section{Introduction}

According to the 2011 Population Census, nearly 70 per cent of Uttarakhand population lives in its rural areas. To fulfil their energy demand rural population of Uttarakhand solely depends on natural resources available in the regions. The livelihood of people from hills of Uttarakhand is closely driven by the forest resources for domestic as well as small industrial use. The per capita annual consumption of dry wood in various parts of
Himalaya has been reported to be much higher ranging between 500 to $1200 \mathrm{~kg}{ }^{[9]}$. It was also suggested that the fuel wood is the most extracted material from the Himalayan forests and its consumption in the Garhwal himalayan ranges between $20-25 \mathrm{~kg}$ per household per day ${ }^{[19]}$.

To fulfil the demand of timber rural population is bound to cut down the tress instead for alternate options like biomass and coal briquettes. Among all the fuel species the 
use of Pinus Roxburghii was found highest ${ }^{[16]}$. The total area under Chir Pine forest in India is estimated to be 0.89 Mha out of which 0.412 Mha lie in Uttarakhand in both Garhwal and Kumaon region ${ }^{[20]}$.

The average availability of pine needles in state varies from 4 to 6 tons per hectare. Pine needles fall off the trees from the middle of March to the onset of the rains and creating a thick carpet of pine needles on the forest floor which are the major threat to the environment, forest biodiversity, and local economy in the entire Himalayan region due to their highlyinflammable 17 nature. Also with this, pine has a tendency of restricting other plants ${ }^{[21]}$. Pine needles are lignocellulosic biomass having calorific value of $20.18 \mathrm{MJ} / \mathrm{kg}$ which is comparable to pine wood with 19.78 $\mathrm{MJ} / \mathrm{kg}^{[12]}$.

Higher calorific value with its biological properties makes it a promising bio- fuel and which can be converted to useful energy in a number of ways such as briquetting and thermochemical conversion etc. Produced solid bio-fuels from pine needles will be of high energy density than its parent material and reduce the risk of forest fire once it is removed from the forest.

The various studies suugests that pine needles can be good source for conversion to biochar through pyrolysis ${ }^{[18]}$. Biochar contains high amount of carbon ${ }^{[10]}$ and can be used as a potential feedstock for solid biofuel preparing biochar briquettes. It was suggested that biochar briquettes can be characterized as carbon rich with high heating value and relatively pollution free solid biofuels ${ }^{[11]}$. In the view of above, the objective of the present study was to investigate the feasibility of pine needle biochar briquetted fuel prepared with different binders and evaluate their physicochemical and thermal properties.

\section{Materials and Methods}

\section{Biochar preparation}

Pine needles are pointed leaves, like a pile of needles, 20 to $35 \mathrm{~cm}$ long, and have a distinc yellow-brown colour when dried. The initial moisture content of the pine needles collected from the forest ranged between of 17 to $20 \%$ which was further reduced up to $8-10 \%$ after 3-4 days of sun drying. Pine needle biochar was prepared using a pyrolysis biochar drum (Fig. 9) available in the Department of Farm Machinery and Power Engineering, College of Technology, Pantnagar. The biochar production unit consist a horizontal pyrolysis drum designed for the conversion of pine needles into biochar and gas products. A centrifugal-type air blower maintaining airflow rate of 40- 50 $\mathrm{m}^{3} \mathrm{~h}^{-1}$ standardized in previous studies was attached with a 700 watts motor for the air supply was used for initial burning of pine needles. The biochar drum has an efficiency of converting around $90 \%$ of pine needles into biochar with recovery of 28-30 \%.

\section{Selection of briquetting machine}

The screw press extruder type Siya Manufacture made briquetting machine was used for preparation of pine needle biochar briquettes (Fig.8). The whole unit mainly consist the mainframe on which driving motor, transmission system and machine are fixed with the means of nut and bolts.

\section{Binder selection}

The low-pressure briquetting requires a binding agent that holds the loose biochar material together. A binder (or additive) can be a liquid or solid that forms a bridge, film, and matrix or causes a chemical reaction to make strong inter-particle bonding. Three different binding material was used for the 
briquetting i.e. soil, cement and lime keeping in view their easy availability in hills of Uttarakhand.

\section{Selection of proposed biochar binder ratio}

The preliminary experiments were conducted to determine the right proportion of pine needles biochar and binders for stable briquettes before preparing with machine. Pine needle biochar briquettes were prepared using three binders which were mixed adequately by hand with a small amount of water for proper binding. The biochar and binders were mixed by weight having a proportion of $10 \%, 20 \% 30 \%, 40 \%$ and $50 \%$. Handmade briquettes of mixture of biochar and binders were made and pressed in the palm to judge the friability of each mixture. These briquettes then were sundried and shattered to observe the strength of briquettes. As per observations, the briquettes prepared with mixture having $10 \%$ binder was formed friable and therefore was not used for the preparation of briquettes. $20-50 \%$ binder level was found appropriate for production of briquettes therefore was selected for study and is shown in Table 1. The three replications for each experiment were conducted in identical conditions for briquettes production. Total thirty six experiments were conducted for the study.

\section{Production of briquettes}

The raw material was fed to the hopper that was conveyed to screw by gravity and vibration forces acting on the machine during operation. The briquetting machine was operated at $128 \mathrm{rpm}$. The material further was pushed forward by means of geometry of screw. The compressed and bounded material was then extruded out from the die in form of briquettes. The unit has output capacity of 22 $\mathrm{kg} / \mathrm{h}$ with low to medium pressure of $1.5-2.5$ MPa.

\section{Properties of biochar briquettes}

\section{Size}

Size of the briquettes was determined by measuring the average length and diameter of briquettes using an INDER make vernier calliper with $0.01 \mathrm{~mm}$ least count

\section{Weight}

Weight of the briquettes was determined by measuring the average weight of prepared briquette samples by using an electronic weighing balance of Citizen made with the maximum capacity of $220 \mathrm{~g}$ and least count of $0.001 \mathrm{~g}$

\section{Bulk density}

The bulk density of the sample was determined as per the ASTM E873-82 $(2013)^{[6]}$, Standard Test Method for Bulk Density of Densified Particulate Biomass Fuels.

\section{Shattering resistance}

The shattering resistance test includes the determination of stability of the relative size of briquette and friability of briquettes. It indicates the hardness and the ability of briquettes to withstand the breakage when handling. As per Standard Test Method of Drop Shatter Test ASTM D440-86 (2002) ${ }^{[7]}$, the known weight and length sample of briquettes were dropped from the height of $1.83 \mathrm{~m}$ on a concrete floor two times. The weights of shattered briquette were noted and the percentage loss of material calculated.

\section{Water absorption resistance test}

Water absorption resistance test is a measure of water absorbed by the briquettes when immersed in water and the test described in 
NAIP, ICAR, (2014) ${ }^{[15]}$ was followed. The briquettes having average length and diameter of $65 \mathrm{~mm}$ and $25 \mathrm{~mm}$ respectively were immersed in water volume for 60 seconds at room temperature. The percentage of water gain by each briquette calculated.

\section{Degree of densification}

The degree of densification is defined as the percentage increase in the density of raw material by the briquetting procedure. Degree of densification indicates the ability of the biomass to get bounded. It was determined by using formula proposed by Birwatkar et al., $(2014)^{[8]}$ with stand the breakage when handling. As per Standard Test Method of Drop Shatter Test ASTM D440-86 (2002) ${ }^{[7]}$, the known weight and length sample of briquettes were dropped from the height of $1.83 \mathrm{~m}$ on a concrete floor two times. The weights of shattered briquette were noted and the percentage loss of material calculated.

\section{Water absorption resistance test}

Water absorption resistance test is a measure of water absorbed by the briquettes when immersed in water and the test described in NAIP, ICAR, (2014) ${ }^{[15]}$ was followed. The briquettes having average length and diameter of $65 \mathrm{~mm}$ and $25 \mathrm{~mm}$ respectively were immersed in water volume for 60 seconds at room temperature. The percentage of water gain by each briquette calculated.

\section{Degree of densification}

The degree of densification is defined as the percentage increase in the density of raw material by the briquetting procedure. Degree of densification indicates the ability of the biomass to get bounded. It was determined by using formula proposed by Birwatkar et al., $(2014)^{[8 .]}$

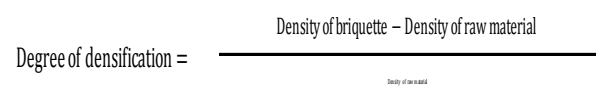

\section{Compressive strength}

A diametrical compression test was performed to determine the compressive strength of briquettes. A single briquette was placed between two flat, parallel platens and an increasing load was applied at a constant rate until the test specimen fails by cracking. The load at fracture is read off from a recorded stress-strain curve, which is the compressive strength and reported as force or stress. The $100 \mathrm{kN}$ capacity ADMET Inter face make (1220AJ-25K-B model) Universal Testing Machine 106 was used for compressive strength ${ }^{-}$and was calculated as per relationship shown below:

Where,

$\mathrm{F}=$ compressive strength $(\mathrm{MPa})$

$\mathrm{P}=$ maximum load applied to the sample $(\mathrm{N})$

$A=$ cross-sectional area of the sample $\left(\mathrm{mm}^{2}\right)$

\section{Proximate analysis for chemical characteristics of biochar briquettes}

Proximate analysis of biochar briquettes were carried out to determine the moisture, volatile matter, fixed carbon and ash content. Moisture, volatile matter and ash content were determined according to ASTM D 3173-03 $(2008)^{[2]}$, ASTM D 3175-07 (2007) $)^{[3]}$ and ASTM D 3174-02 (2002) ${ }^{[4]}$ protocols, respectively on a dry basis. The fixed carbon content was calculated by the difference in weight.

\section{Thermal characteristics}

The calorific value of pine needle biochar briquettes was determined by using an automatic Toshniwal make with model 
number CC01/M3 microprocessor controlled bomb calorimeter according to ASTM E71187 (2004). The burning capacity rate and thermal efficiency test was determined by the method described in IS 13152 (Part I): $1991^{[13]}$. The thermal efficiency of a stove is defined as the ratio of heat actually utilized to the heat theoretically produced by burning a given quantity of briquettes. A known amount of water is used to heat by the known quantity of briquettes fuel. The amount of water and the quantity of fuel is determined by the burning capacity rate. An infrared thermometer, Smart Sensor make of AR 330 model with range between $-32-330^{\circ} \mathrm{C}$ was used to measure the temperature of water.

The observed results were statistically analyzed with 2-factorial-CRD for both parameters i.e. type of binder and the ratio using a Design-Expert software version 10 to determine their significance properties of briquettes.

\section{Results and Discussion}

The biochar briquettes were prepared for different combination of biochar and binder as mention in Table 1 and the obtained results of physical, chemical and thermal properties of biochar briquettes with different combination of biochar and binder are shown in Table 2.

\section{Physical properties of biochar briquettes}

The physical properties of biochar briquettes were recorded after sun drying for 4 days. The average length of briquettes prepared with soil as a binder varied from 59.0 to $69.7 \mathrm{~mm}$ while the average weight varied from 17.2 to 21.8 g. Similarly, the average length of briquettes prepared with cement and lime as a binder varied from 64.3 to $73.0 \mathrm{~mm}$ and 62.0 to $77.3 \mathrm{~mm}$ respectively. Further, the average weight of briquettes prepared with cement and lime as binder varied between 25.0 to $38.3 \mathrm{~g}$ and 24.7 to $32.7 \mathrm{~g}$ respectively. It was found that the longest briquettes were formed for biochar and lime ratios while smaller briquettes were formed for biochar and soil ratios. It was due to that the soil is coarser than the lime that resulted in less adhesion of material and breaking of briquettes during collection. The results also indicate that heavier briquettes were formed for biochar and cement mixture as cement is heavier as compared to other binders used in biochar briquette production.

Effect of different binder and their composition on bulk density and degree of densification of briquettes

The highest density of biochar briquettes was found to be $435.58 \mathrm{~kg} \mathrm{~m}^{-3}$ for ratio $\mathrm{B} 50: \mathrm{C} 50$ which comprise equal percentage $50 \%$ of biochar and cement as binder whereas lowest density was observed for $310.68 \mathrm{~kg} \mathrm{~m}^{-3}$ for ratio B80:L20 which has $80 \%$ of biochar and $20 \%$ of lime on weight basis. The maximum degree of densification was found to be 206.31\% in ratio B60:C40 (60\% biochar and $40 \%$ cement) while the lowest degree of densification was $77.79 \%$ for ratio B80:S20 (80\% biochar and $20 \%$ soil). It is evident from the Fig.1 (a) that with an increase in percentage of binder, the bulk density of briquettes also increased due to the fact that binders have higher bulk density as compared to bulk density of biochar. Further, Fig.1 (b) revealed that the degree of densification followed the similar trend as the bulk density i.e. maximum degree of densification was observed for biochar briquettes prepared with highest binder ratio for all type of binders. However, the highest bulk density and degree of densification was found for briquettes which were prepared with cement and lime as binder as they are finer as compared to soil and have good quality adhesion as well holding the biochar particle together resulting 
in higher bulk density and degree of densification.

Effect of different binder and their composition on shattering resistance of briquettes

It is evident from the Table 2 that the composition of biochar with soil (B80:S20) has the lowest resistance to shattering i.e.
$39.61 \%$ whereas the combination of biochar with lime (B50:L50) has the highest shattering resistance $(90.6 \%)$.

The results also indicate (Fig.2) that lower the biochar content in briquettes, higher was the shattering resistance of briquettes. This was due to the fact that higher content of binders could produce briquettes which are more cohesive.

Table.1 Composition of raw materials

\begin{tabular}{|c|c|c|}
\hline S. No. & Biochar-Binder Ratio & Description \\
\hline 1 & B80:S20 & Biochar $80 \%+$ Soil $20 \%$ \\
\hline 2 & B70:S30 & Biochar 70\% + Soil $30 \%$ \\
\hline 3 & B60:S40 & Biochar $60 \%+$ Soil $40 \%$ \\
\hline 4 & B50:S50 & Biochar 50\% + Soil $50 \%$ \\
\hline 5 & B80:C20 & Biochar $80 \%+$ Cement $20 \%$ \\
\hline 6 & B70:C30 & Biochar $70 \%+$ Cement $30 \%$ \\
\hline 7 & B60:C40 & Biochar $60 \%+$ Cement $40 \%$ \\
\hline 8 & B50:C50 & Biochar $50 \%+$ Cement $50 \%$ \\
\hline 9 & B80:L20 & Biochar $80 \%+$ Lime $20 \%$ \\
\hline 10 & B70:L30 & Biochar $70 \%$ + Lime $30 \%$ \\
\hline 11 & B60:L40 & Biochar $60 \%+$ Lime $40 \%$ \\
\hline 12 & B50:L50 & Biochar $50 \%+$ Lime $50 \%$ \\
\hline
\end{tabular}


Table.2 Physicochemical and thermal characteristics of biochar briquetted fuel

\begin{tabular}{|c|c|c|c|c|c|c|c|c|c|c|}
\hline \multirow[t]{2}{*}{$\begin{array}{c}\text { Biochar- } \\
\text { Binder }\end{array}$} & BD, & DOD, & SR, & WAR, & CS, & MC, & VM, & $\mathbf{A C}$, & FC, & \multirow[t]{2}{*}{$\begin{array}{l}\text { CV, } \\
\text { MJ }\end{array}$} \\
\hline & \multirow{2}{*}{$\mathrm{kgm}^{-3}$} & \multirow[t]{2}{*}{$\%$} & \multirow[t]{2}{*}{$\%$} & \multirow[t]{2}{*}{$\%$} & \multirow[t]{2}{*}{ MPa } & \multirow[t]{2}{*}{$\%$} & \multirow[t]{2}{*}{$\%$} & \multirow[t]{2}{*}{$\%$} & \multirow[t]{2}{*}{$\%$} & \\
\hline Ratio & & & & & & & & & & $\mathrm{kg}-1$ \\
\hline B80:S20 & 312.0 & 77.79 & 39.61 & 0 & 0.32 & 2.63 & 17.98 & 37.67 & 41.72 & 23.26 \\
\hline B70:S30 & 337.88 & 81.56 & 55.32 & 0 & 0.39 & 3.38 & 15.28 & 38.20 & 43.15 & 19.73 \\
\hline B60:S40 & 405.22 & 133.02 & 64.05 & 0 & 0.45 & 4.31 & 13.68 & 39.25 & 42.77 & 17.15 \\
\hline B50:S50 & 422.97 & 124.59 & 72.07 & 0 & 0.52 & 4.55 & 11.57 & 47.03 & 36.85 & 16.38 \\
\hline B80:C20 & 362.92 & 111.46 & 45.63 & 63.22 & 0.35 & 1.93 & 28.65 & 28.71 & 40.71 & 21.17 \\
\hline B70:C30 & 380.67 & 141.09 & 60.15 & 74.69 & 0.40 & 2.14 & 25.44 & 34.00 & 38.42 & 17.91 \\
\hline B60:C40 & 408.70 & 206.31 & 74.79 & 54.19 & 0.52 & 2.4 & 22.84 & 35.35 & 39.42 & 16.93 \\
\hline B50:C50 & 435.58 & 205.17 & 80.92 & 85.74 & 0.59 & 2.7 & 21.37 & 48.73 & 27.2 & 14.05 \\
\hline B80:L20 & 310.68 & 143.57 & 77.37 & 97.77 & 0.38 & 0.03 & 36.88 & 23.13 & 39.96 & 24.42 \\
\hline B70:L30 & 330.41 & 153.94 & 76.29 & 82.48 & 0.43 & 0.07 & 36.45 & 23.89 & 39.59 & 20.41 \\
\hline B60:L40 & 395.60 & 168.17 & 89.02 & 93.95 & 0.56 & 0.1 & 33.83 & 33.05 & 33.02 & 18.72 \\
\hline B50:L50 & 400.25 & 170.87 & 90.65 & 78.50 & 0.65 & 0.13 & 31.36 & 37.18 & 31.33 & 16.90 \\
\hline
\end{tabular}

B: Biochar, S: Soil, C: Cement, L: Lime, BD: Bulk density, DOD: Degree of densification, SR: Shattering resistance, WAR: Water absorption resistance, CS: Compressive strength, MC: Moisture content, VM: Volatile matter, AC: Ash content, FC: Fixed carbon, CV: Calorific value

Table.3 Burning capacity rate and thermal efficiency of biochar briquetted fuel

\begin{tabular}{|l|l|l|l|l|}
\hline $\begin{array}{l}\text { Sr. } \\
\text { No. }\end{array}$ & Biochar-Binder Ratio & $\begin{array}{l}\text { Burning } \\
\text { (kcal/h) }\end{array}$ & capacity rate & $\begin{array}{l}\text { Thermal efficiency } \\
(\mathbf{\%})\end{array}$ \\
\hline $\mathbf{1 .}$ & B70:S30 & 1892.70 & 23.36 \\
\hline $\mathbf{2 .}$ & B60:S40 & 1541.58 & 22.10 \\
\hline 3. & B70:C30 & 1388.21 & 21.92 \\
\hline 4. & B60:C40 & 1163.64 & 18.53 \\
\hline $\mathbf{5 .}$ & B70:L30 & 1442.85 & 23.27 \\
\hline 6. & B60:L40 & 1301.85 & 20.54 \\
\hline
\end{tabular}


Fig.1 (a, b) Effect of different composition on bulk density and degree of densification of biochar briquettes
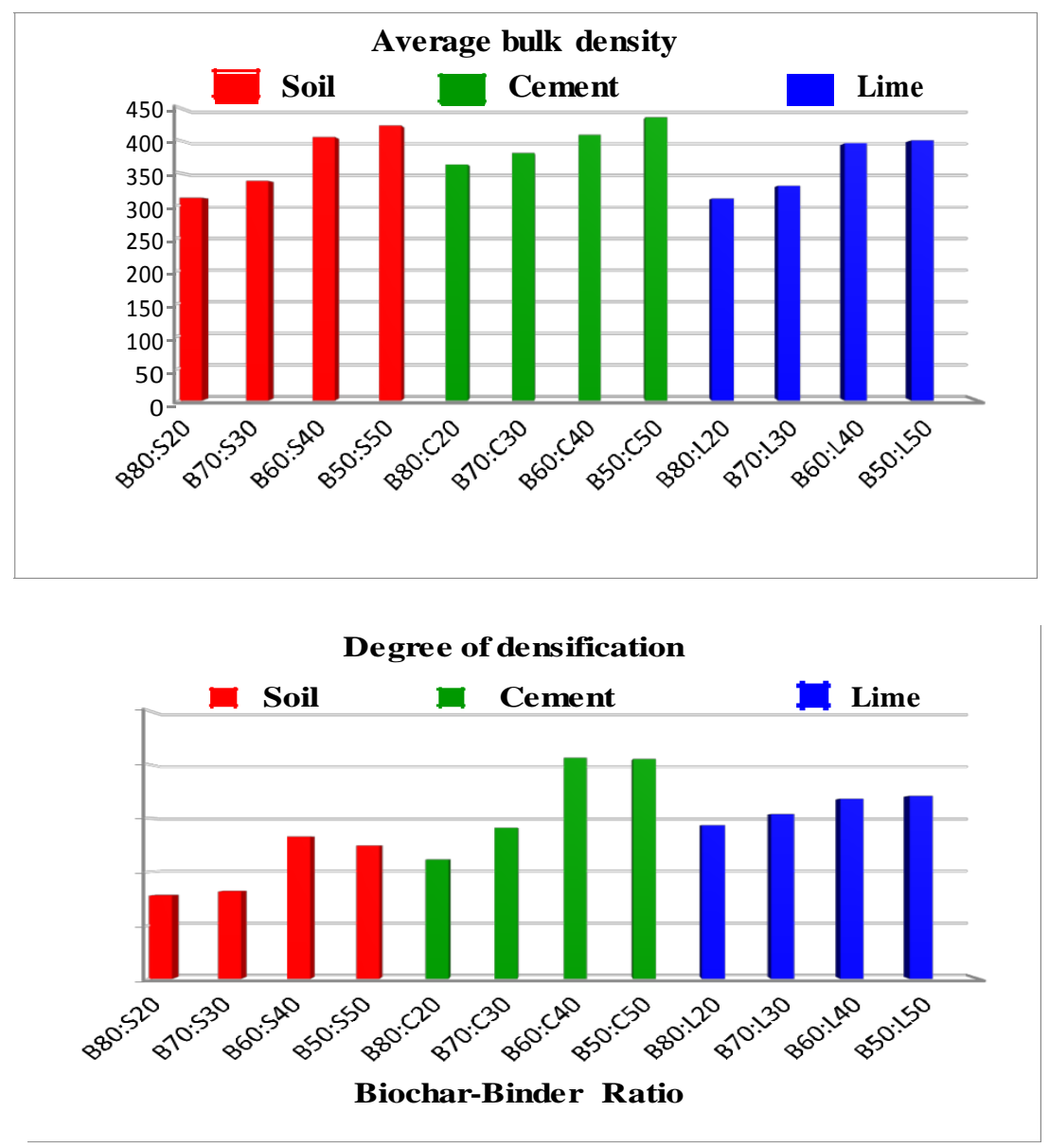

Figure 1 (b)

Fig.2 Effect of different composition on shattering resistance of biochar briquettes

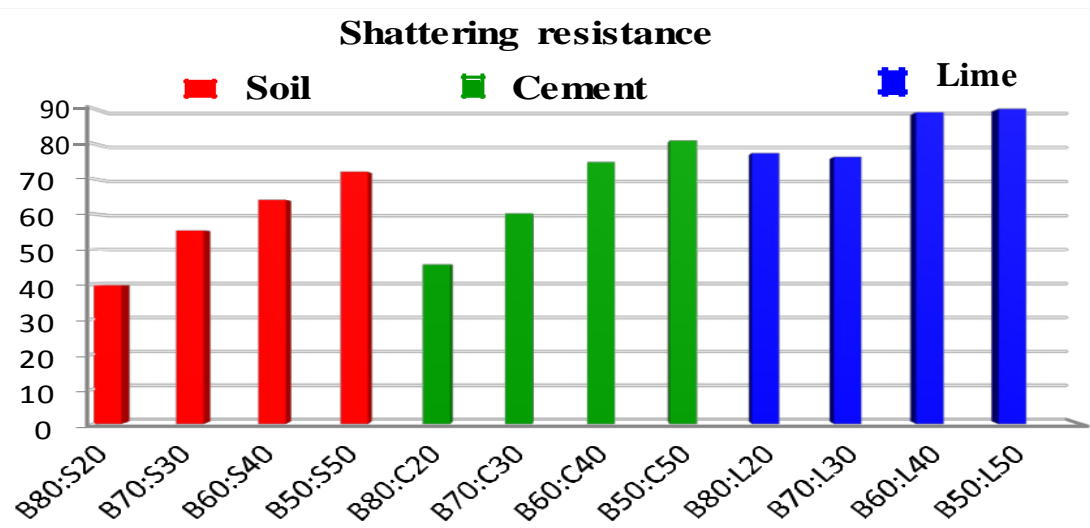

Biochar-Binder Ratio 
Fig.3 Effect of different composition on water resistance of biochar briquettes

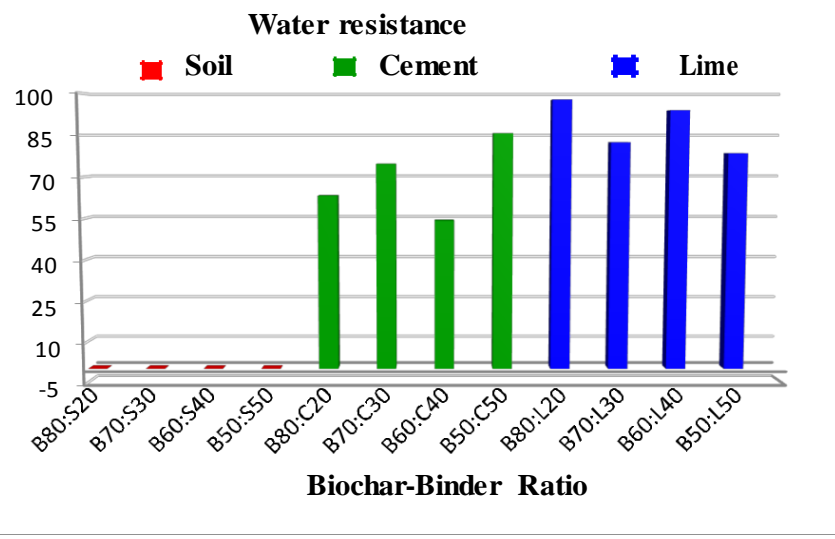

Fig.4 Effect of different composition on compressive strength of biochar briquettes

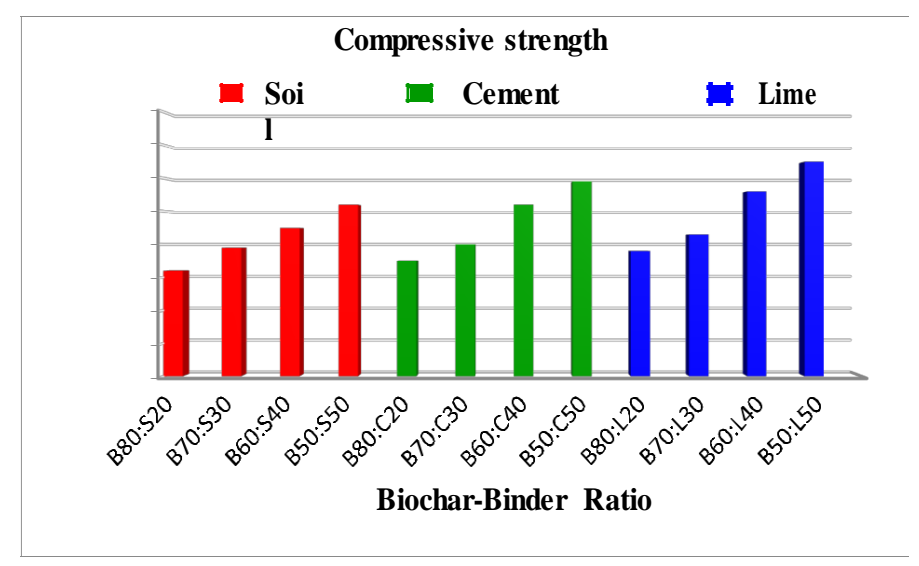

Fig.5 (a, b, c, d) Effect of different composition on chemical properties of biochar briquettes

Fig.5 (a)

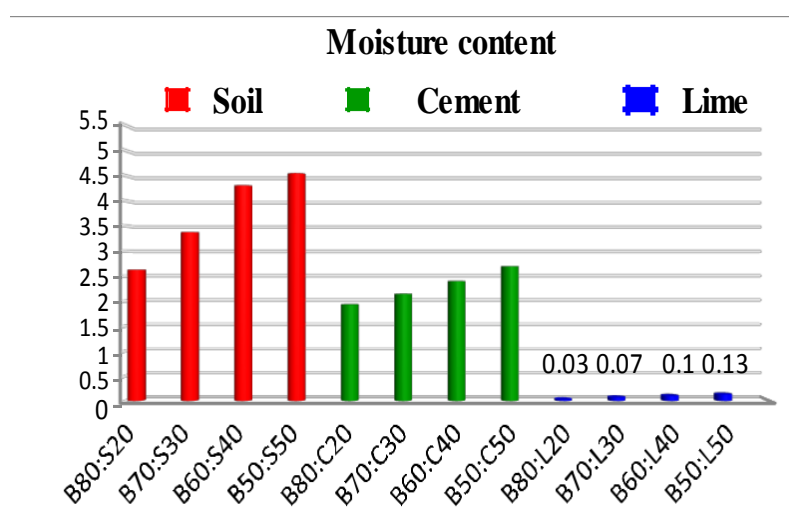


Fig.5 (b)

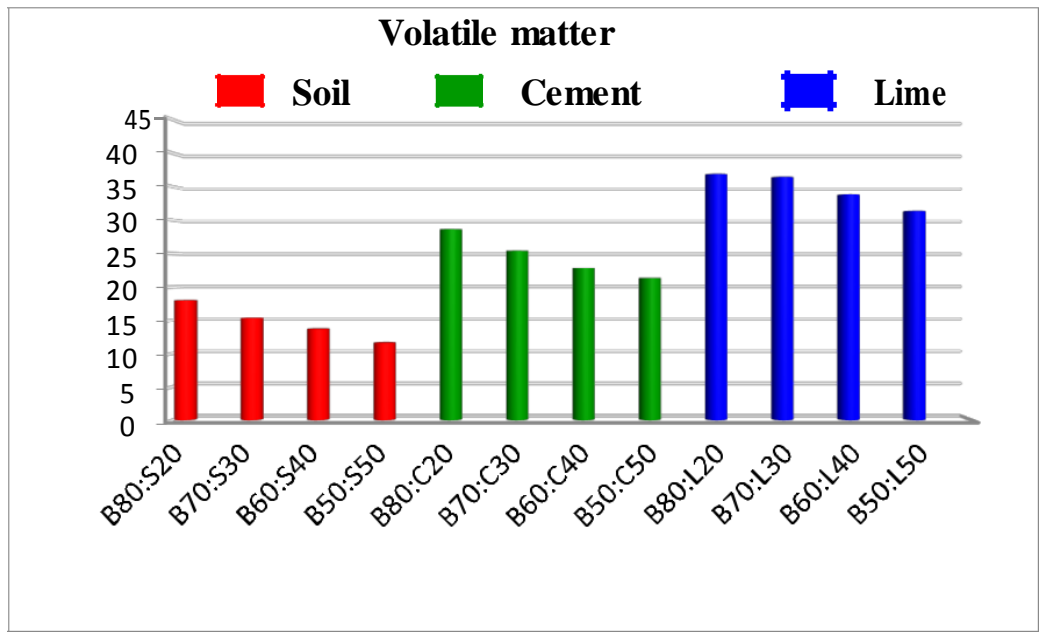

Fig.5 (c)

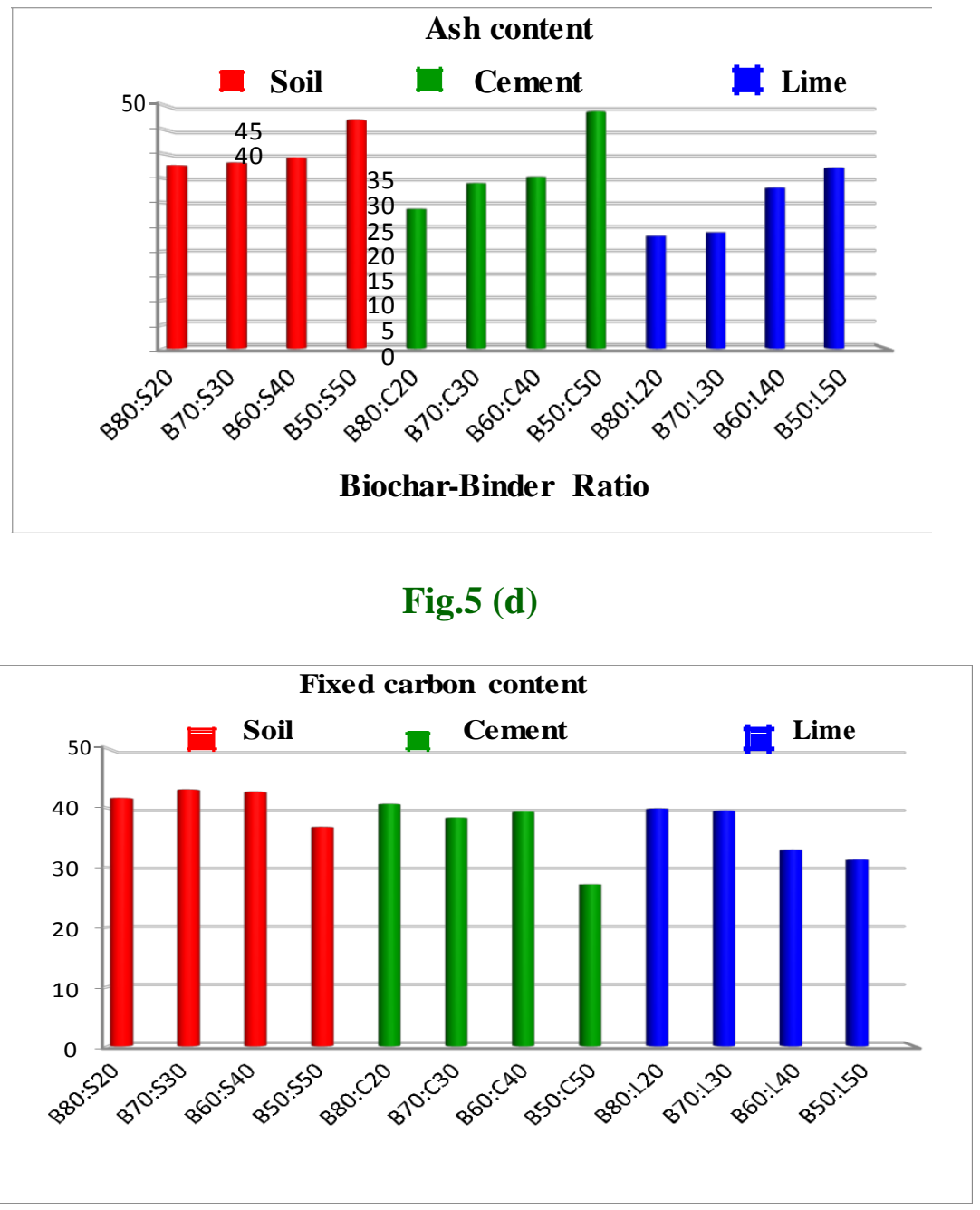


Fig.6 (a, b, c) Effect of different composition on thermal properties of biochar briquettes Fig.6 (a)

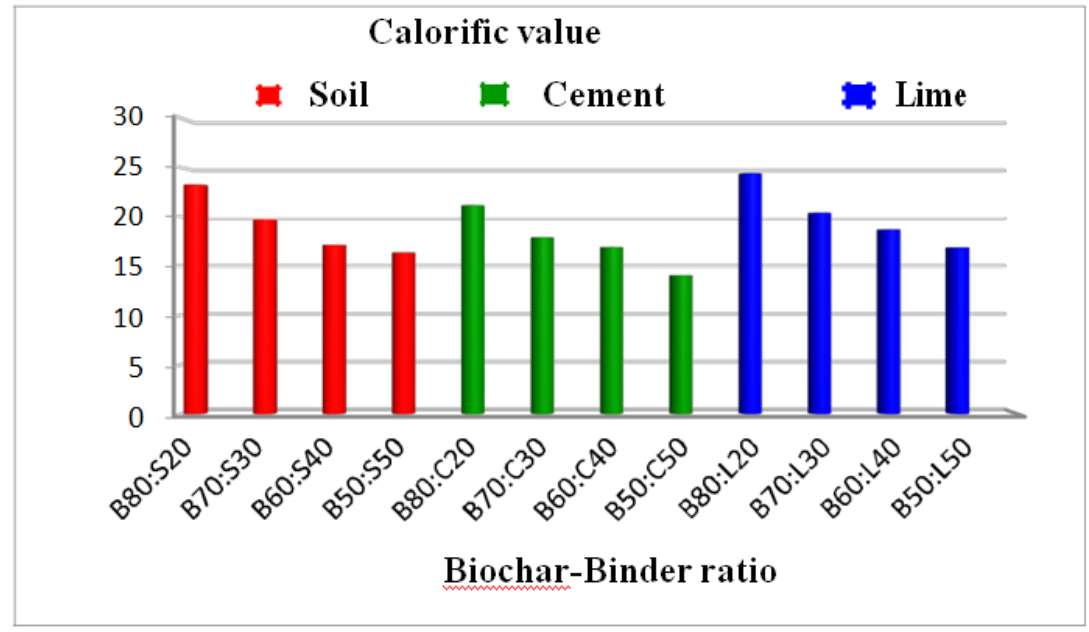

Fig.6 (b)

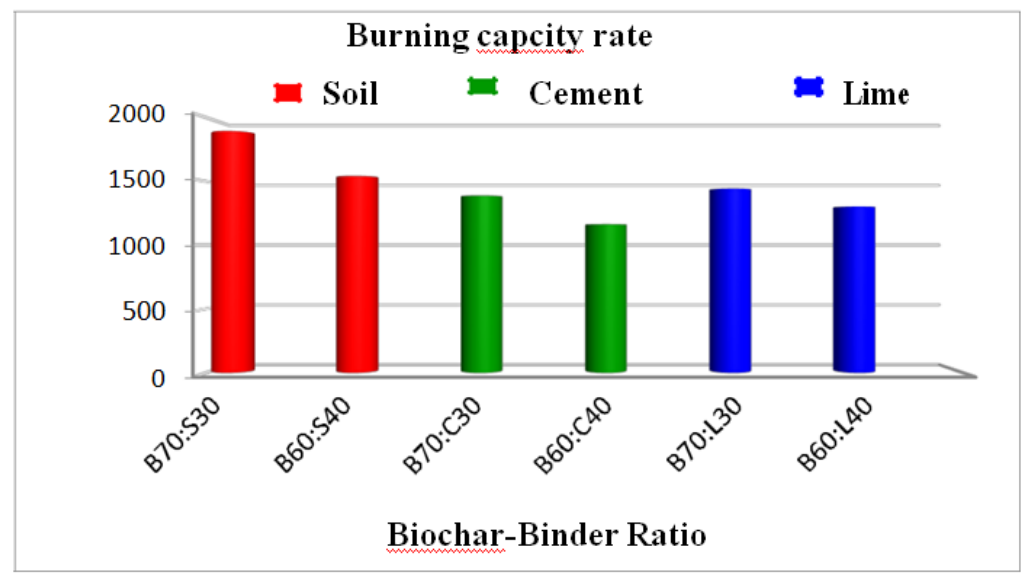

Fig.6 (c)

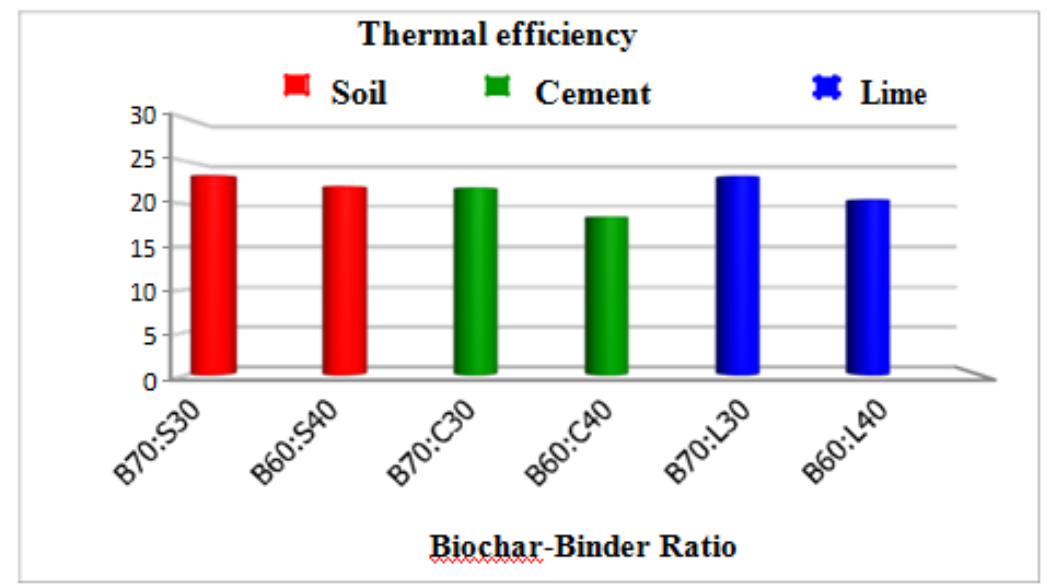


Fig.8 Motor operated screw press briquetting machine

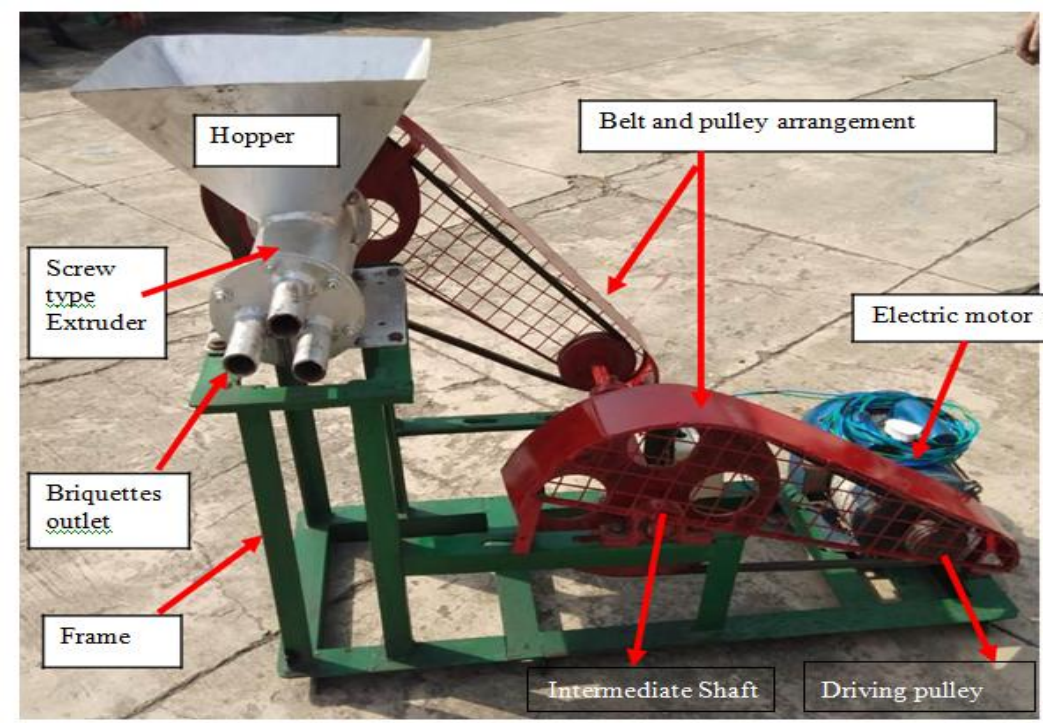

Fig.9 Biochar drum used for production of pine needle biochar

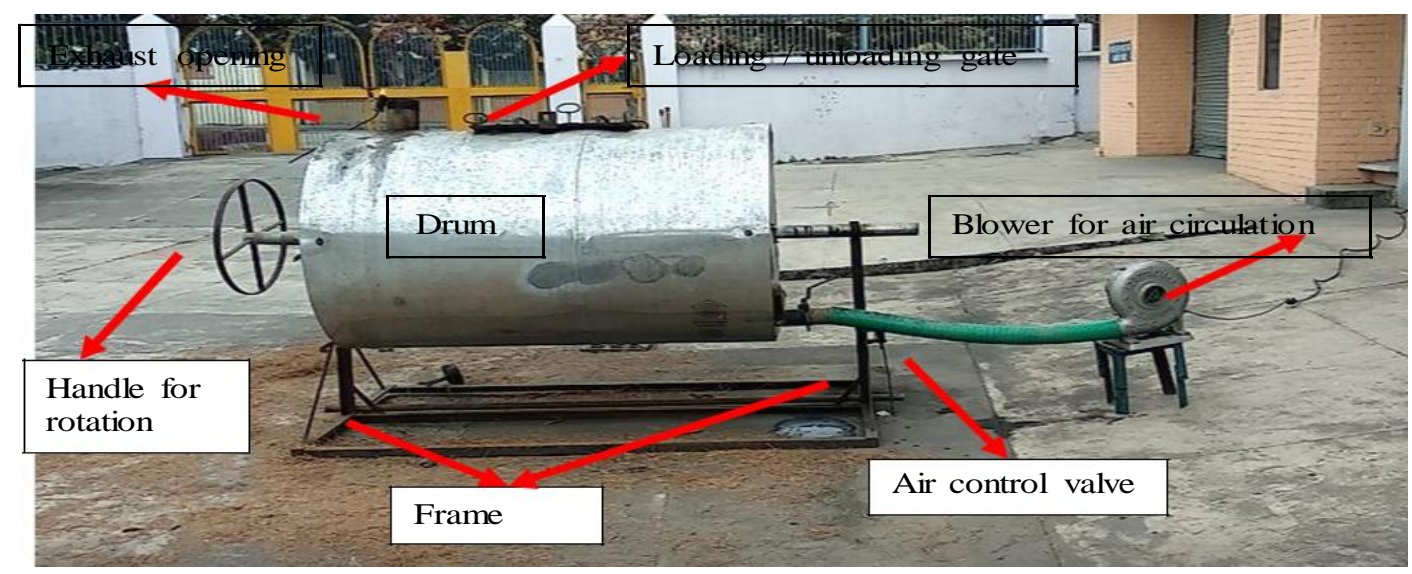

Effect of different binder and their composition on water absorption resistance of briquettes

It has been found that the water resistance of biochar briquettes varied from 54.19 to 85.74 $\%$ and 78.50 to $97.77 \%$ for briquettes prepared with cement and lime respectively. The highest resistance to water was shown by biochar briquette prepared with lime as binder (B80:L20) i.e. $97.77 \%$. As indicated by Fig. 3 the biochar briquettes prepared using soil as binder were highly susceptible to water. It was also observed that biochar-soil briquettes slowly withered after 15-20 seconds when completely submerged into water. It was due to the reason that biochar and soil both are highly porous as compared to cement and lime and allowed water to penetrate resulting in biochar withering and weight loss of briquettes. However, the whole briquette was not dissolved.

\section{Effect of different binder and their composition on compressive strength of briquettes}

The Fig. 4 indicates that compressive strength increased with increase in binder content in biochar briquettes for all treatments. The 
maximum compressive strength was found $0.65 \mathrm{MPa}$ for B50:L50 (50 \% biochar and $50 \%$ lime) whereas the minimum strength was found $0.32 \mathrm{MPa}$ for B80:S20 (80\% biochar and $20 \%$ soil). It is due to that the higher amount of binding agent resulted in more surface area increasing adhesive forces and interlocking of more particles ultimately increasing the strength of briquettes.

Effect of different binder and their composition on chemical properties of briquettes

The results shown in Table 2 and Fig. 5 (a) indicate that the biochar briquettes prepared with lime as binder had lowest moisture content i.e. ranging between 0.03 to $0.13 \%$, whereas the ratio B50:S50 had highest moisture content of $4.55 \%$. The negligible water content in biochar briquettes prepared with lime as a binder was probably due to the reason that lime has low water retaining capacity due to its low porosity. It is evident from the Fig. 5 (a) that with decrease in biochar content in the briquettes, the moisture content increases. It was due to the reason that the biochar is hydrophobic in nature therefore higher content of biochar in briquettes resulted in low moisture content. Hence, it was observed that as binder content increased in briquettes the moisture content also increased. The moisture content of briquettes was observed to similar that reported in other studies ${ }^{[14,17]}$.

The highest volatile matter was found 36.88 $\%$ for ratio B80:L20 (80\% biochar and $20 \%$ lime) while the lowest value was $11.57 \%$ for B50:S50 (50\% of biochar and soil). It is evident from the Fig. 5 (b) that the biochar briquettes prepared with lime as binder had the highest volatile matter.

Further, the briquettes prepared with cement also follow the similar trend with briquettes prepared with lime and soil. It was observed that the average ash content varied from 37.67 to $47.035,28.71$ to $48.73 \%$ and 23.13 to $37.18 \%$ for biochar briquettes prepared with soil, cement and lime respectively. The maximum ash content was found $48.73 \%$ for ratio $\mathrm{B} 50: \mathrm{C} 50$ (50\% of biochar and cement) while the lowest value of $23.13 \%$ was shown for ratio B80:L20 (80 \% biochar and 20\% lime).

As indicated by the Fig. 5 (c) that the ash content in briquettes increased progressively with an increase in binder content from 20 to $50 \%$. The progressive increase was due to the addition of higher amount of non combustible material in the form of binder. It was observed from the figure that the soil had very high proportion of ash content; however the results also shared that the tar formation was negligible for briquettes prepared with soil as a binder. The highest and lowest value of fixed carbon was obtained for biochar briquettes prepared with soil and cement as binder i.e. $43.15 \%$ for ratio B70:S30 (70\% biochar and $30 \%$ soil) and $27.20 \%$ for ratio B50:C50 (50\% biochar and cement) respectively. As shown in Fig. 5 (d) the fixed carbon content decreased as binder proportion was increased. It may be due to decrease in biochar proportion in briquette since it had higher fixed carbon content around $66 \%$. The fixed carbon content plays an important role as its higher value increase the burning time of briquetted fuel.

Effect of different binder and their composition on burning rate and thermal efficiency of stove with biochar briquettes

As seen from the Table 2 the calorific value of the biochar briquettes varied from 14.05 to $24.42 \mathrm{MJkg}^{-1}$. The highest calorific value was obtained for ratio B80:L20 (80\% biochar and $20 \%$ lime) i.e. $24.42 \mathrm{MJ} \mathrm{kg}^{-1}$ while the lowest calorific value was found to be $14.05 \mathrm{MJ} \mathrm{kg}^{-1}$ 
for ratio B50:C50 (50\% of biochar and binder). It is evident from the Fig. 6 (a) that the calorific value of biochar briquettes decreased with an increase of binder proportion in briquettes. It was due to the reason that more addition of non combustible material to briquettes in form of binder that do not possess any calorific value, since biochar hold higher calorific value about 29 $\mathrm{MJ} \mathrm{kg}^{-1}$. However, soil has high heat retaining capacity $^{[1]}$ and has shown the high calorific value as compared to briquettes prepared with cement.

The burning capacity rate was only carried out for biochar briquettes with higher calorific value as well as good physical and chemical properties that are desirable for charcoal briquetted fuel. Therefore, six samples were selected for study and results are given below in Table 3.

The burning capacity rate of biochar briquettes prepared with lime as binder varied from 1301.85 to $1442.85 \mathrm{kcal} \mathrm{h}^{-1}$. As Fig. 6 (b) and Table 3 shows the maximum burning rate capacity was obtained for biochar briquettes prepared with soil as binder for the ratio $\mathrm{B} 70: \mathrm{S} 30$ (70\% biochar and $30 \%$ soil) i.e. $1892.70 \mathrm{kcal} \mathrm{h}^{-1}$ whereas the lowest burning rate was observed for ratio $\mathrm{B} 60: \mathrm{C} 40$ (60\% biochar and $40 \%$ cement) which is $1163.64 \mathrm{kcal} \mathrm{h}^{-1}$. The obtained trend of burning capacity rate indicated that the burning capacity rate decreased with the increased in binder proportion in briquettes. The higher burning capacity rate of biochar briquettes prepared with soil may be due to the higher porosity of briquettes as soil and biochar both are coarse material which enables easy percolation of oxygen and outflows of combustion due to low bonding force ${ }^{[17]}$ as compared to other binding agents such as cement and lime. It was suggested that more fuel might be required for heating and cooking with briquettes produced with cement and lime as binder. The above table shows that the biochar briquettes prepared with soil as binder had the highest thermal efficiency of $23.36 \%$. Whereas it ranged from 18.53 to $21.92 \%$ for biochar briquettes prepared with cement and 20.54 to $23.27 \%$ for briquettes prepared with lime.

It was found from the statistical analysis that effect of different binder was found significant on all the properties of briquettes at $5 \%$ level of significance. Further, the effect of different biochar binder ratio was also analyzed and found significant on all the properties at $5 \%$ level of significance.

\section{Conclusion}

The following conclusions are drawn from the study:

1. The pine needle biochar briquetting can help in reducing the forest fires as well as deforestation in hills of Uttarakhand.

2. The prepared biochar briquettes were good quality and can replace wood and coal in the region.

3. The highest bulk density was found 435.58 $\mathrm{kg} \mathrm{m}^{-3}$ for B50:C50 (50\% of biochar and cement) whereas the highest shattering resistance was found $90.65 \%$ for the B50:L50 that had equal percentage of biochar and lime.

4. The highest calorific value was obtained for ratio B80:L20 (80\% biochar and 20\% lime) i.e. $24.42 \mathrm{MJ} \mathrm{kg}^{-1}$ followed by $23.26 \mathrm{MJ}$ $\mathrm{kg}^{-1}$ for ratio B80:S20 (80\% biochar and 20\% soil).

5. The highest heat retaining capacity around four to five hours was found for biochar briquettes prepared with soil as binder. 


\section{References}

1. Abu-Hamdeh, N.H. and Reeder, R.C., Soil thermal conductivity effects of density, moisture, salt concentration, and organic matter. Soil science society of America Journal, 2000; 64(4), pp.1285-1290.

2. ASTM D3173-03. Standard Test Method for Moisture in the Analysis Sample of Coal and Coke, ASTM International, West Conshohocken, PA (2008).

3. ASTM D3174-02, Standard Test Method for Ash in the Analysis Sample of Coal and Coke from Coal, ASTM International, West Conshohocken, PA, 2002.

4. ASTM D3175-07, Standard Test Method for Volatile Matter in the Analysis Sample of Coal and Coke, ASTM International, West Conshohocken, PA, 2007

5. ASTM D440-86(2002), Standard Test Method of Drop Shatter Test for Coal, ASTM International, West Conshohocken, PA, 1986.

6. ASTM E711-87(2004), Standard Test Method for Gross Calorific Value of Refuse-Derived Fuel by the Bomb Calorimeter (Withdrawn 2004), ASTM International, West Conshohocken, PA, 1987.

7. ASTM E873-82(2013), Standard Test Method for Bulk Density of Densified Particulate Biomass Fuels, ASTM International, West Conshohocken, PA, 2013.

8. Birwatkar, V.R, Khandetod, Y.P, Mohod, A.G, Dhande, K.G, Source, O.E, Dapoli, T, Machinery, F. and Dapoli, T. Physical and thermal properties of biomass briquetted fuel. Indian Journal of Science and Technology, 2014; 2, pp.55-62.

9. Campbell, J.G. and Bhattarrai, T.N.
People and Hills of Nepal preliminary presentation of findings of community forestry household and ward leader survey, 1984; Project paper 10, HMG/UNDP/FAO community forestry Development Project Nepal.

10. Demirbas, A., Şahin-Demirbaş, A. and Hilal-Demirbaş. A. Briquetting properties of biomass waste materials. Energy Sources, 2004; 26, 83-91.

11. Didem Özçimen and Ayşegül ErsoyMeriçboyu. Characterization of biochar and bio-oil samples obtained from carbonization of various biomass materials, Renewable Energy, 2010; 35, (6), 1319-1324.

12. Font, R, Conesa, J.A, Moltó, J. and Muñoz. M. Kinetics of pyrolysis and combustion of pine needles and cones. Journal of Analytical and Applied Pyrolysis, 2009. 85(1-2), pp.276-286.

13. IS 13152-1. Solid bio-mass chulha, part 1: portable (metallic). MED 4: Non-Conventional Energy Sources, Bureau of Indian Standards; New Delhi, 1991.

14. J.M. Onchieku, B.N. Chikamai and M.S. Rao. Optimum Parameters for the Formulation of Charcoal Briquettes Using Bagasse and Clay as Binder, European Journal of Sustainable Development, 2012; 1, 3, 477-492.

15. N. Mahar, N. Joshi, P. Pandey and P. C. Joshi. Resource Utilization by the Local Communities around a Protected Forest in Western Himalaya, Glimpses of Forestry Research in the Indian Himalayan Region 2011; pp. 131-138.

16. NAIP, ICAR, Value Chain on Biomass based Decentralized Power Generation for Agro Enterprises. Final Report, National Agricultural Innovation Project. Central Institute of Agricultural Engineering (Indian 
Council of Agricultural Research), Bhopal, India, 2014.

17. O. A.Oyelaran, B. J. Olorunfemi, O. M. Sanusi, A. O. Fagbemigun, O. Balogun. Investigating the Performance and Combustion Characteristics of Composite Bio-coal Briquette, Journal of Materials and Engineering Structures, 2018; 5, 173184.

18. Saâdaoui, M., Mahjoub Saïd, N., Mhiri, H., Caminat, P., Le Palec, G., \& Bournot, P. Study of the behavior of a flame resulting from the combustion of pine needles in a cylindrical basket. International Journal of Thermal
Sciences, 2008; 47(3), 293-305.

19. Singh, G., Rawat, G.S. and Verma, D. Comparative study of fuel wood consumption by villagers and seasonal dhaba owners in the tourist affected regions of Garhwal Himalaya, India. Energy Policy, 2010; 38: 1895-1899.

20. Singh, V. and S. Kumar. Seed quality as affected by mid cone diameter in Pinus roxburghii Sarg. Indian Forester, 2004; 130(7), 757-761.

21. Sinha, B. Introduction of the European Pines in the Himalayas: A Brief Note. ENVIS Bulletin, Himalayan Ecology, 2002; 10(1), 7-9, ISSN: 0971-7447.

\section{How to cite this article:}

Akanksha Kumain, T. K. Bhattacharya and Hemant Kumar Sharma 2020. Physicochemical and Thermal Characteristics of Pine Needle Biochar Briquetted Fuel using Soil, Lime and Cement as a Binder. Int.J.Curr.Microbiol.App.Sci. 9(10): 3675-3690.

doi: https://doi.org/10.20546/ijcmas.2020.910.425 